\title{
The relationships between body composition and cardiovascular risk factors in young Australian men
}

\author{
Selma C Liberato ${ }^{1 *}$, Louise Maple-Brown ${ }^{1}$, Josefina Bressan² and Andrew P Hills ${ }^{3}$
}

\begin{abstract}
Introduction: Cardiovascular (CV) disease is a leading cause of global mortality. Despite clear evidence of the coexistence of several risk factors in young people as children and an understanding of the importance of the health behaviors in controlling CV disease, there are limited data on the relationships between risk factors and CV disease in young people. Therefore further study is required.

Objective: This study aimed to investigate associations among body composition, health behaviors and CV risk factors in young Australian men.

Methods: Thirty five healthy men aged 18-25 years had their blood pressure (BP), blood lipids, body composition, resting metabolic rate (RMR), physical activity, dietary intake and cardiorespiratory fitness assessed.

Results: Participants were categorised according to the percentage of body fat into two groups: lean and overweight men. There were no between-group differences in the biochemical indicators except that overweight men had lower HDL-C compared to lean men. Both groups had similar mean energy, protein, fat, carbohydrate and alcohol intake, RMR, physical activity level (PAL) and energy expenditure (EE). Most of the participants (65.7\%) had $\mathrm{LDL} \geq 2.5 \mathrm{mmol} / \mathrm{L}$. Other common individual risk factors were body fat $\geq 20 \%(42.9 \%)$, waist circumference $\geq 88 \mathrm{~cm}$ (28.6\%), PAL $<1.8$ (22.9\%) and systolic BP $\geq 130 \mathrm{mmHg}$ (20\%). The mean number of CV risk factors was lower among men having a high intake of monounsaturated fatty acids (MUFA, $>12 \%$ of the energy intake) regardless of whether they were overweight or lean and did not seem to differ according to the source of MUFA consumed.

Conclusions: It is a serious concern to observe such a high percentage of CV risk factors in a group of apparently healthy young men. The likelihood of multiple CV risk factors is greater among those with high body fatness and Iow MUFA intake. Intake of MUFA favorably affects CV risk factors regardless of the source.
\end{abstract}

Keywords: Blood lipids, Dietary fatty acids, Body composition, Young men, Dietary intake, Cardiovascular risk factors

\section{Introduction}

Cardiovascular (CV) disease is a leading cause of global mortality, accounting for almost 17 million deaths annually [1-3]. Twenty five percent of the deaths in 2008 due to non-communicable disease from which $\mathrm{CV}$ disease accounted for almost $50 \%$, occurred before the age of 60 [4]. If $\mathrm{CV}$ accounts for $37.7 \%$ of all deaths [5], almost $10 \%$ are likely to be premature. The rate of $\mathrm{CV}$ disease is

\footnotetext{
* Correspondence: selma.liberato@gmail.com

${ }^{1}$ Menzies School of Health Research, Charles Darwin University, Darwin, Australia

Full list of author information is available at the end of the article
}

accelerating worldwide and one of the causes is the dramatic increase in the prevalence of obesity with its related complications of hypertension, hyperlipidemia, diabetes and atherosclerotic vascular disease [1]. Any level of overweight appears to increase $\mathrm{CV}$ disease risk. The greater the obesity level [6], the body fatness [7] or the abdominal obesity [8], the greater the risk of developing CV disease. Cardiovascular health has commonly been measured by considering the coexistence or clustering of several risk factors in an individual. Traditional CV risk factors include high blood pressure (BP), high serum low density lipoprotein cholesterol (LDL-C), elevated glucose, advancing age,

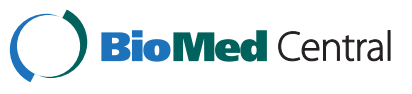


tobacco smoking, male gender, family history of premature $\mathrm{CV}$ disease, and other components of the metabolic syndrome such as low levels of high density lipoprotein cholesterol (HDL-C). Other CV risk factors include physical inactivity, low socioeconomic status, elevated psychosocial stress, excessive alcohol and inappropriate diet [3,9-12].

A well balanced diet should contain adequate amounts of protein, fat, carbohydrate, vitamins, minerals, and water. For the maintenance of good nutrition in healthy, normally active persons, there are recommended daily levels of essential nutrients. The largest proportion of the daily energy intake (EI) should be in the form of carbohydrates [13] with approximately $12-20 \%$ of the daily EI from protein [13] and 20-35\% from fat [13-15]. On the other hand, high intakes of fat (33-40\% of EI), particularly monounsaturated fatty acids (MUFA) from olive oil, as in the Mediterranean diet, have been associated with favorable blood lipid profile [14] and reduced predicted coronary heart disease risk in diabetic men [16].

Despite clear evidence of the coexistence of several risk factors in young people as children [17] and an understanding of the importance of the health behaviors in controlling CV disease, there are limited data on the relationships between risk factors and $\mathrm{CV}$ disease in young people. In particular, detailed assessment of $\mathrm{CV}$ risks and health behaviours in those with early onset overweight may enhance our understanding of premature CV disease risk. Therefore, we sought to investigate associations between health behaviors and $\mathrm{CV}$ risk factors in young Australian men aged 18-25 years. We hypothesized that individuals with early onset overweight would display more CV risk factors, fewer healthy and more unhealthy behaviors than those of healthy weight.

\section{Methods}

Thirty five healthy men aged 18-25 y, from the local community in the city of Brisbane, Australia volunteered for the study. Participants were recruited by flyers posted in shopping centers and education centers as well advertisement in local newspapers. Inclusion criteria to participate in the study were age between 18 and 25 years and absence of any chronic disease. Queensland University of Technology Human Research Ethics Committee approved the participant recruitment and data collection procedures. Methods have been previously described in detail [18]. In brief, anthropometric measures including body weight, height and composition, waist circumference (WC) and hip circumference were undertaken. Body mass index (BMI) was calculated as weight (kg) divided by height ${ }^{2}\left(\mathrm{~m}^{2}\right)$. Body composition was measured by dual-energy X-ray absorptiometry (DEXA) (DPX-Plus; Lunar Corp, Madison, WI). The participant removed shoes, any materials that could attenuate the $\mathrm{x}$-ray beam, such jewellery, watches and clothes with zippers and laid on his back in the centre of the table. Participants remained motionless in the supine position while the scanning arm of the DEXA passed over their body from head to toe in parallel 1-cm strips. DEXA measurements were made using a constant potential $x$-ray source of $76 \mathrm{kVp}$ and a cerium filter that produces dualenergy peaks of 38 and $62 \mathrm{keV}$. The soft tissue mass (fat and lean tissue) is measured pixel-by-pixel as a beam of photons penetrates the participant's body. Body fat content was determined from DEXA whereas body fat-free mass was calculated by subtracting body fat content from body weight. The DEXA values were used to classify participants into two groups: a) lean (body fat $<20 \%$ ) and b) overweight (body fat $\geq 20 \%$ ). BMI $>25$ and $>30 \mathrm{~kg} / \mathrm{m}^{2}$ correspond to body fat percentage values of approximately $20 \%$ and $25 \%$ in men, respectively [19-21]. The DEXA values divided by squared height in meters (\%body fat mass $/ \mathrm{m}^{2}$ ) was also used to classify the participants into groups: lean (body fat $/$ height $^{2}<6 \mathrm{~kg} / \mathrm{m}^{2}$ ) and overweight (\%body fat $/$ height $^{2} \geq 6 \mathrm{~kg} / \mathrm{m}^{2}$ ) $[22,23]$.

Resting metabolic rate (RMR) was assessed by continuous open-circuit indirect calorimetry. A Deltatrac II metabolic cart (Datex-Ohmeda Corp., Helsinki, Finland http://www.hospitalnetwork.com/doc/Deltatrac-II-MetabolicMonitor-0001) was used to assess RMR of half of the participants. Due to technical problems, the Moxus $\mathrm{O}_{2}$ system (AEI Technologies, Pennsylvania, USA) was used to assess the RMR of the remaining participants. RMR measures are less than $100 \mathrm{kcal} / \mathrm{d}$ lower using the Deltatrac compared to Moxus according to a study conducted in the same laboratory using the same equipments [24]. A similar proportion of lean and overweight participants were assessed using each of the methods and therefore likelihood of measurement bias was reduced.

Sitting BP was assessed taking one measurement by the same investigator after 10-min rest with a sphygmomanometer. Hypertension was defined as a mean systolic $\mathrm{BP}>130 \mathrm{mmHg}$, and/or diastolic $\mathrm{BP}>85 \mathrm{mmHg}$ [25]. Following an overnight fast of at least $8 \mathrm{~h}$, a blood sample was collected for total cholesterol (TC), HDL-C, LDL-C and triglycerides (TG) determination using reagents from Roche Diagnostics (Indianapolis, IN). The measurement of TC and LDL-C were based on the determination of $\Delta^{4}$ cholestenone after enzymatic cleavage of the cholesterol ester by cholesterol esterase, conversion of cholesterol by cholesterol oxidase, and subsequent measurement by Trinder reaction of the hydrogen peroxide formed [26]. A combination of a sugar compound with detergent was used to selectively determine LDL-C in serum [26]. The HDL-C was determined directly in serum using polyethylene glycol-modified enzymes and dextran sulfate [26]. Low density/high density lipoprotein cholesterol ratio is a risk indicator with greater predictive value than isolated 
parameters used independently, particularly LDL-C [27]. Total cholesterol $<4.0 \mathrm{mmol} / \mathrm{L}[28], \mathrm{LDL}-\mathrm{C}<2.5 \mathrm{mmol} / \mathrm{L}$ [28], HDL-C $>1.0 \mathrm{mmol} / \mathrm{L}$ [28], TG<1.7 mmol/L [28] and LDL-C/HDL-C ratio $<3$ [27] were target values.

Both food intake and physical activity were assessed over four days. Food intake was assessed by recording household estimates into a food record and entered into the Foodworks (v.3.02) nutrient analysis software (Xris software Pty Ltd. Brisbane, Australia, http://www.xyris. com.au). Macronutrients were expressed as source of energy (percentage of daily EI). Source of MUFA intake was identified and quantified. Physical activity was assessed by physical activity records using nine categories of physical activity intensity (1-9) [29] for each 15min period throughout the day. The four-day physical activity record scores $1,2,3,4,5,6,7,8$ and 9 correspond to $1,1.5,2.3,2.8,3.3,4.8,5.6,6$ and 7.8 metabolic equivalents (MET) [29], respectively. Using measured RMR, the total daily energy expenditure (EE) was calculated for each participant after accounting for each of the 96 15-min periods of a day and multiplying the score by its specific MET value. Physical activity level (PAL) was calculated by dividing total EE by RMR. Physical activity energy expenditure (PAEE) was calculated by subtracting RMR from EE.

Cardiorespiratory fitness was measured by a continuous speed, incremental grade running test on a treadmill. Participants were fitted with a Polar Coded Transmitter $^{\mathrm{TM}}$ and receiver (Polar Electro, Kempele, Finland), a Hans-Rudolf headset (with two-way breathing valve and pneumotach) and a nose clip. After a 4min warm-up at $3.5 \mathrm{mph}, 0 \%$ grade, speed was increased to a previously determined comfortable speed, which was the same until the end of the test. Thereafter, the treadmill slope was increased by $2 \%$ every min, till the participants reached exhaustion. The rating of perceived exertion using the Borg scale [30] was obtained during each stage and participants were encouraged to achieve a rating of 18 or higher as an indicator of maximal effort. Maximal oxygen uptake $\left(\mathrm{VO}_{2 \max }\right)$ was assessed using a MOXUS Modular $\mathrm{O}_{2}$ System (AEI Technologies, Pennsylvania, USA). $\mathrm{VO}_{2 \max }$ was achieved when the difference between the last 2 completed stages determined by the average of the last 30 -sec period before the load increased was $<1.6 \mathrm{ml} / \mathrm{kg}$.min or when both heart rate $\pm 10 \mathrm{bpm}$ of 220 - age and respiratory exchange ratio $>1.15$ were achieved. $\mathrm{VO}_{2 \max }$ was defined as the highest observed value averaged across 15 seconds in a completed stage. When the participant did not reach $\mathrm{VO}_{2 \max }, \mathrm{VO}_{2}$ peak oxygen uptake, the highest observed value of $\mathrm{VO}_{2}$ was considered in analysis. $\mathrm{VO}_{2}$ was expressed per $\mathrm{kg}$ body weight.

The number of cardiovascular risk factors was calculated by counting how many of the following five factors were present: hypertension (systolic $\mathrm{BP} \geq 130 \mathrm{~mm} \mathrm{Hg}$ and/or diastolic $\mathrm{BP} \geq 85 \mathrm{~mm} \mathrm{Hg}[25]$, high ( $\geq 3.0) \mathrm{LDL}-\mathrm{C} /$ HDL-C ratio [27], high $(\geq 1.7 \mathrm{mmol} / \mathrm{L}) \mathrm{TG}$ [31], high $(\geq 88 \mathrm{~cm})$ WC [25], low $(<1.8)$ PAL [32]. National Health and Medical Research Council [13] does not set adequate intake (AI), recommended dietary intake (RDA) or upper limit (UL) values for MUFA. Therefore the median percentage of EI as MUFA (12\%) was chosen as a cutoff to divide participants in low and high MUFA intake.

Data are presented as means and standard deviations. The Student's $t$ test was used to compare data. Statistical analysis was performed using Statistic for Windows 5.5 software. A P value less than 0.05 was considered as statistically significant.

\section{Results}

Using percentage of body fat to classify study participants into lean and overweight groups, three participants with a BMI $>25 \mathrm{~kg} / \mathrm{m}^{2}$ were not overweight based on body composition assessment as their body fat percentage assessed by DEXA ranged from $12.5 \%$ to $19.2 \%$. Similarly, five participants with a $\mathrm{BMI}<25 \mathrm{~kg} / \mathrm{m}^{2}$ had a body fat $>20 \%$ (data not shown). Participant characteristics are outlined in Table 1. As expected, overweight participants (body fat $\geq 20 \%$ ) had higher body weight, BMI, circumference measurements and body fat mass than lean participants (body fat $<20 \%$ ). Lean and overweight participants had similar fat-free mass (FFM) levels, but lean participants had proportionally more FFM than overweight participants did. There were no between-group differences in the biochemical indicators except that overweight participants had lower HDL-C compared to lean participants. The mean TC and LDL-C levels were above the target levels of $4.0 \mathrm{mmol} / \mathrm{L}$ and $2.5 \mathrm{mmol} / \mathrm{L}$, respectively, even among the lean participants (Table 1).

Using percentage of body fat $/ \mathrm{m}^{2}$ to classify study participants into lean and overweight groups, two lean participants having $\%$ of body fat $<20 \%$ were classified as overweight because they had \%body fat $/ \mathrm{m}^{2} \geq 6 \mathrm{~kg} / \mathrm{m}^{2}$. Participant characteristics are outlined in Table 1. Compared to the results using \%body fat to classify the participants into adiposity levels, all body composition, blood pressure and blood lipid results were similar to the results using \%body fat $/ \mathrm{m}^{2}$ except for HDL-C where the difference was no longer significant and for the $\mathrm{TC} /$ HDL-C ratio where the higher levels in overweight compared to lean participants became significant (Table 1).

Using percentage of body fat to classify study participants into lean and overweight groups, both groups had similar mean energy, protein, fat, carbohydrate and alcohol intake (Table 2). Carbohydrate contributed less than 50\% of EI. Lean participants consumed more energy relative to BW than did the overweight participants. Both groups had similar mean RMR, PAL and EE. Lean participants expended 
Table 1 Body composition, blood pressure (BP) and blood lipid measures of young men

\begin{tabular}{|c|c|c|c|c|c|c|}
\hline Characteristic & Lean $^{1}(n=20)^{2}$ & Overweight $^{1}(n=15)^{2}$ & P values $^{3}$ & Lean $^{4}(n=18)^{2}$ & Overweight $^{4}(n=17)^{2}$ & $\mathrm{P}$ values ${ }^{3}$ \\
\hline Age (years) & $21.2(1.7)^{5}$ & $22.5(2.6)$ & 0.102 & $20.8(1.2)$ & $22.7(2.6)$ & $<0.001$ \\
\hline Body weight (kg) & $71.1(10.4)$ & $85.9(12.2)$ & $<0.001$ & $70.3(10.3)$ & $85.0(12.1)$ & $<0.001$ \\
\hline Height (m) & $1.75(0.07)$ & $1.78(0.07)$ & 0.252 & $1.75(0.07)$ & $1.77(0.07)$ & 0.579 \\
\hline Body mass index $\left(\mathrm{kg} / \mathrm{m}^{2}\right)$ & $23.2(2.8)$ & $27.2(3.0)$ & $<0.001$ & $22.8(2.5)$ & $27.2(2.9)$ & $<0.001$ \\
\hline Waist circumference $(\mathrm{cm})$ & $78.3(2.8)$ & $88.5(8.1)$ & $<0.001$ & $77.5(4.7)$ & $88.1(7.8)$ & $<0.001$ \\
\hline Hip circumference (cm) & $98.8(5.9)$ & $107.3(5.7)$ & $<0.001$ & $97.8(5.3)$ & $107.3(5.4)$ & $<0.001$ \\
\hline Fat mass (kg) & $9.6(3.8)$ & $22.0(6.0)$ & $<0.001$ & $9.1(3.5)$ & $21.1(6.1)$ & $<0.001$ \\
\hline Body fat (\%) & $13.4(4.0)$ & $25.7(5.8)$ & $<0.001$ & $12.8(3.7)$ & $24.9(5.8)$ & $<0.001$ \\
\hline Fat-free mass (kg) & $58.1(7.7)$ & $60.3(9.2)$ & 0.448 & $57.9(7.8)$ & $60.2(9.0)$ & 0.419 \\
\hline Fat-free mass (\%) & $86.6(4.0)$ & $74.3(5.8)$ & $<0.001$ & $87.2(3.7)$ & $75.1(5.8)$ & $<0.001$ \\
\hline Systolic BP (mmHg) & $120.3(9.0)$ & $124.3(11.2)$ & 0.248 & $120.7(9.4)$ & $123.3(10.8)$ & 0.458 \\
\hline Diastolic BP (mmHg) & $57.3(7.2)$ & $60.1(7.0)$ & 0.247 & $56.8(7.4)$ & $60.2(6.7)$ & 0.165 \\
\hline TC (mmol/L) & $4.33(0.92)$ & $4.63(1.06)$ & 0.375 & $4.26(0.93)$ & $4.66(1.01)$ & 0.222 \\
\hline $\mathrm{HDL}-\mathrm{C}(\mathrm{mmol} / \mathrm{L})$ & $1.46(0.29)$ & $1.30(0.16)$ & 0.043 & $1.47(0.31)$ & $1.31(0.16)$ & 0.082 \\
\hline LDL-C (mmol/L) & $2.57(0.83)$ & $2.78(0.76)$ & 0.448 & $2.49(0.82)$ & $2.84(0.76)$ & 0.07 \\
\hline LDL-C/HDL-C & $1.83(0.70)$ & $2.20(0.69)$ & 0.135 & $1.78(0.70)$ & $2.21(0.67)$ & 0.07 \\
\hline TC/HDL-C & $3.05(0.80)$ & $3.62(0.92)$ & 0.058 & $3.00(0.81)$ & $3.60(0.88)$ & 0.04 \\
\hline Triglycerides (mmol/L) & $0.86(0.30)$ & $1.41(1.49)$ & 0.172 & $0.86(0.31)$ & $1.34(1.40)$ & 0.167 \\
\hline
\end{tabular}

TC Total Cholesterol, HDL-C High-density lipoprotein cholesterol, LDL-C Low-density lipoprotein cholesterol.

${ }^{1}$ Lean (\%body fat $<20 \%$ ) and overweight (\%body fat $\geq 20 \%$ ).

${ }^{2}$ Number of participants.

${ }^{3}$ Probability of means being different by $\mathrm{T}$ test.

${ }^{4}$ Lean (body fat $/$ height $^{2}<6 \mathrm{~kg} / \mathrm{m}^{2}$ ) and overweight (\%body fat $/ \mathrm{height}^{2} \geq 6 \mathrm{~kg} / \mathrm{m}^{2}$ ).

${ }^{5}$ Standard Deviation.

more energy relative to BMI and more physical activity energy relative to body weight than overweight participants. Lean participants had higher cardio respiratory fitness $\left(\mathrm{VO}_{2 \max }\right)$ compared to overweight participants (Table 2). Four participants had measurements $\mathrm{VO}_{2 \max }$ missing due to technical problems with the equipment or due to inability of the participant to complete the last session of measurements. Most of the participants (65.7\%) had LDL-C $\geq 2.5 \mathrm{mmol} / \mathrm{L}$. Other common individual risk factors were body fat $\geq 20 \%$ (42.9\%), cardiorespiratory level $\mathrm{VO}_{2 \max }<51$ $\mathrm{mL}$ of $\mathrm{O}_{2} / \mathrm{min}$ (41.9\%), $\mathrm{WC} \geq 88 \mathrm{~cm}(28.6 \%), \quad \mathrm{PAL}<1.8$ (22.9\%), and systolic $\mathrm{BP} \geq 130 \mathrm{mmHg}(20 \%)$. The least common individual risk factors were $\mathrm{TG} \geq 1.7 \mathrm{mmol} / \mathrm{L}(8.6 \%)$, LDL-C/HDL-C ratio $>3$ (8.6\%) and HDL-C $<1 \mathrm{mmol} / \mathrm{L}$ (5.7\%). None of the participants had diastolic BP $\geq 85$ $\mathrm{mmHg}$.

Using \% of body fat $/ \mathrm{m}^{2}$ to classify study participants into lean and overweight groups, all reported food intake, resting metabolic rate and physical activity results were similar to the results using \%body fat to classify the participants into adiposity groups except for PAL where the high PAL of the lean compared to the overweight participants became significant.

Using percentage of body fat to classify study participants into lean and overweight groups, the mean number of CV risk factors was lower among participants having a high intake of MUFA ( $>12 \%$ of EI) regardless of whether they were overweight or lean. The percentage of participants with $\mathrm{CV}$ risk factors was higher among those reporting low $(<12 \%$ of EI) intakes of MUFA compared to those reporting high intakes of MUFA (Figure 1A). Same findings were observed using \%body fat $/ \mathrm{m}^{2}$ to classify the study participants into adiposity levels (Figure 1B).

Using percentage of body fat to classify study participants into lean and overweight groups, the mean number of $\mathrm{CV}$ risk factors was comparable between both participants consuming MUFA mainly from plant foods (plant/animal MUFA ratio $>1$ ) and participants consuming MUFA mainly from animal foods (plant/animal MUFA ratio $<1$ ) regardless of whether they were overweight or lean (Figure 2A). Same findings were observed using \%body fat $/ \mathrm{m}^{2}$ to classify the study participants into adiposity levels (Figure 2B).

\section{Discussion}

A high percentage of $\mathrm{CV}$ risk factors, particularly high LDL-C levels and low levels of physical activity and aerobic fitness was observed in this group of young healthy participants. As expected, overweight (body fat $\geq 20 \%$ ) had higher body weight, BMI, circumference measurements 
Table 2 Reported food intake, resting metabolic rate (RMR), daily energy expenditure (EE) (kcal/day), physical activity energy expenditure (PAEE) (kcal/day), physical activity level (PAL) and oxygen consumption maximum $\left(\mathrm{VO}_{2 \mathrm{max}}\right)$ in young men

\begin{tabular}{|c|c|c|c|c|c|c|}
\hline Characteristic & $\operatorname{Lean}^{1}(n=20)^{2}$ & Overweight $^{1}(n=15)^{2}$ & $\begin{array}{c}\mathrm{P} \\
\text { values }^{3}\end{array}$ & $\operatorname{Lean}^{4}(n=18)^{2}$ & Overweight $^{4}(n=17)^{2}$ & $\begin{array}{c}\mathrm{P} \\
\text { values }^{3}\end{array}$ \\
\hline Energy intake ${ }^{5}, \mathrm{~kJ} / \mathrm{d}$; kcal/d & $\begin{array}{c}11379(2249)^{7} ; 2720 \\
(537)\end{array}$ & $\begin{array}{c}11172(2383) ; 2670 \\
\text { (570) }\end{array}$ & 0.795 & $\begin{array}{c}11384(2195) ; 2724 \\
(525)\end{array}$ & $\begin{array}{c}10868(2386) ; 2600 \\
(571)\end{array}$ & 0.51 \\
\hline $\mathrm{El} / \mathrm{BW}, \mathrm{kJ} / \mathrm{kg} ; \mathrm{kcal} / \mathrm{d}$ & $162.8(35.1) ; 38.95(8.4)$ & $131.4(29.3) ; 31.4(7.01)$ & 0.008 & $166.36(7.8) ; 39.8(7.8)$ & $130.8(30.5) ; 31.3(7.3)$ & $<0.001$ \\
\hline Protein (\% of El) & $16.2(2.4)$ & $17.6(5.0)$ & 0.334 & $16.6(2.2)$ & $17.0(4.9)$ & 0.72 \\
\hline Fat (\% of El) & $32.4(3.9)$ & $32.0(6.8)$ & 0.852 & $32.2(3.8)$ & $32.3(6.6)$ & 0.96 \\
\hline Saturated (\%) & $13.2(2.6)$ & $12.5(3.7)$ & 0.520 & $13.1(2.4)$ & $12.6(3.8)$ & 0.67 \\
\hline PUFA (\%) & $4.5(0.8)$ & $4.7(1.2)$ & 0.477 & $4.5(0.8)$ & $4.7(1.2)$ & 0.41 \\
\hline MUFA (\%) & $12.0(1.6)$ & $11.7(2.8)$ & 0.743 & $11.9(1.7)$ & $11.8(2.7)$ & 0.92 \\
\hline Plant/animal ratio & $0.80(0.76)$ & $0.93(0.86)$ & 0.636 & $0.89(0.8)$ & $0.92(0.81)$ & 0.62 \\
\hline Carbohydrate (\%) & $46.3(5.8)$ & $48.4(9.5)$ & 0.688 & $47.0(5.6)$ & $48.6(9.2)$ & 0.52 \\
\hline Alcohol (\%) & $4.0(4.9)$ & $2.0(4.2)$ & 0.201 & $4.2(5.1)$ & $2.0(4.0)$ & 0.17 \\
\hline $\mathrm{RMR}, \mathrm{kJ} / \mathrm{d} ; \mathrm{kcal} / \mathrm{d}$ & $\begin{array}{c}7724(1178) ; 1846 \\
(283)\end{array}$ & 8279 (1103); 1979 (264) & 0.166 & $\begin{array}{c}7687(4924) ; 1839 \\
(283)\end{array}$ & $\begin{array}{c}8235(1108) ; 1970 \\
(265)\end{array}$ & 0.17 \\
\hline $\mathrm{EE}^{5}, \mathrm{~kJ} / \mathrm{d} ; \mathrm{kcal} / \mathrm{d}$ & $\begin{array}{c}15051(2693) ; 3598 \\
\text { (644) }\end{array}$ & 15212 (2433); 3636 582) & 0.856 & $\begin{array}{c}15214(2763) ; 3640 \\
(661)\end{array}$ & $\begin{array}{c}14992(2375) ; 3587 \\
(568)\end{array}$ & 0.80 \\
\hline $\begin{array}{l}\mathrm{EE} / \mathrm{BMI}^{5}, \mathrm{~kJ} / \mathrm{d} \cdot \mathrm{m}^{2} / \mathrm{kg} ; \mathrm{kcal} / \mathrm{d} \text {. } \\
\mathrm{m}^{2} / \mathrm{kg}\end{array}$ & 650 (98); 155 (23) & $563(91) ; 135(22)$ & 0.011 & $\begin{array}{c}666.3(88.2) ; 159.4 \\
(21.1)\end{array}$ & $\begin{array}{c}555.1(86.9) ; 132.8 \\
(20.8)\end{array}$ & $<0.001$ \\
\hline PAEE (EE - RMR) $)^{5}, \mathrm{~kJ} / \mathrm{d} ; \mathrm{kcal} / \mathrm{d}$ & $\begin{array}{c}7327(1739) ; 1751 \\
(415.6)\end{array}$ & $\begin{array}{c}6934(1695.8) ; 1657 \\
(405.3)\end{array}$ & 0.508 & $\begin{array}{c}7524(1710) ; 1800 \\
(409)\end{array}$ & $\begin{array}{c}6755(1655) ; 1616 \\
(396)\end{array}$ & 0.19 \\
\hline PAEE / BW 5 , kJ/d/kg; kcal/d/kg & $104(23) ; 25(6)$ & $82(22) ; 20(5)$ & 0.007 & $107.4(20.9) ; 25.7(5.0)$ & $80.67(25.7) ; 19.3(5.0)$ & $<0.001$ \\
\hline $\mathrm{PAL}^{5}$ & $1.95(0.16)$ & $1.84(0.19)$ & 0.078 & $1.97(0.13)$ & $1.82(0.19)$ & $<0.001$ \\
\hline $\mathrm{VO}_{2 \max }\left(\mathrm{ml} \text { of } \mathrm{O}_{2} / \mathrm{kg} / \mathrm{min}\right)^{6}$ & $55.62(5.88)$ & $46.30(5.97)$ & $<0.001$ & $55.8(6.2)$ & $47.4(6.2)$ & $<0.001$ \\
\hline
\end{tabular}

EI/BW Energy intake divided by body weight, PUFA Polyunsaturated fatty acids, MUFA Monounsaturated fatty acids, EE / BMI Energy expenditure divided by body mass index, PAEE / BW Physical activity energy expenditure divided by body weight.

${ }^{1}$ Lean (body fat $<20 \%$ ) and overweight (body fat $\geq 20 \%$ ).

${ }^{2}$ Number of participants.

3 Probability of means being different by $\mathrm{T}$ test.

${ }^{4}$ Lean (body fat $/$ height $^{2}<6 \mathrm{~kg} / \mathrm{m}^{2}$ ) and overweight (\%body fat $/$ height $^{2} \geq 6 \mathrm{~kg} / \mathrm{m}^{2}$ ).

${ }^{5}$ Mean of 4 days ( 2 weekdays, Saturday and Sunday).

${ }^{6}$ Estimated in 31 (19 lean having \%body fat $<20 \%$ and 12 overweight having \%body fat $\geq 20 \%$ ) participants.

${ }^{7}$ Standard Deviation.
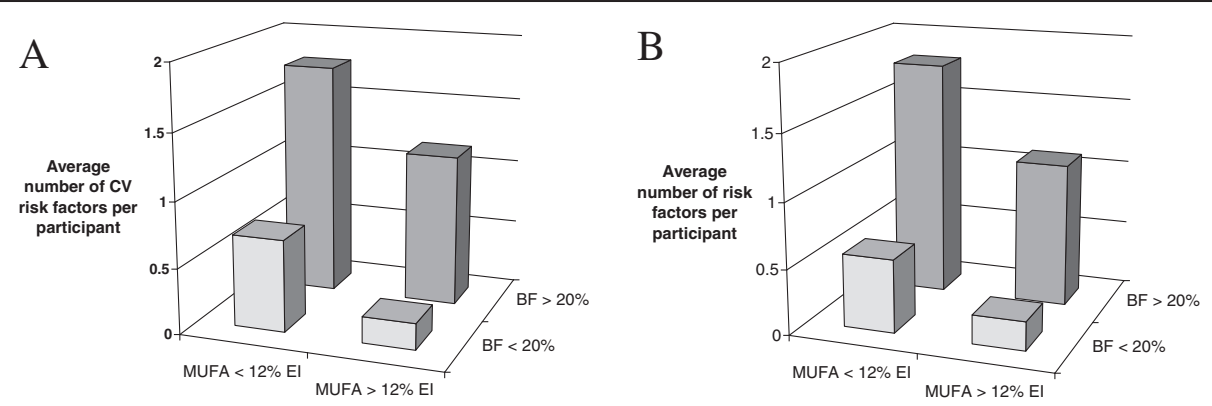

Figure 1 Average number of cardiovascular (CV) risk factors (including waist circumference $>88 \mathrm{~cm}$, physical activity level $<1.8$, diastolic blood pressure $>130 \mathrm{mmHg}$ or systolic blood pressure $>85 \mathrm{mmHg}, \mathrm{LDL}-\mathrm{C} / \mathrm{HDL}-\mathrm{C}$ ratio $>3.0$ and triglycerides $>1.7 \mathrm{mmol} / \mathrm{L}$ ) according to body fat (BF) percentage and monounsaturated fatty acids (MUFA) dietary intake percentage contributing to total energy intake in 19 and 16 men consuming low $(<12 \%)$ and high percentage $(>12 \%)$ of energy intake as MUFA, respectively. A - using \% of body fat from DEXA to classify study participants into lean (20) or overweight (15) groups. B - using \% of body fat from DEXA/m² to classify study participants into lean (18) or overweight (17) groups. 
A

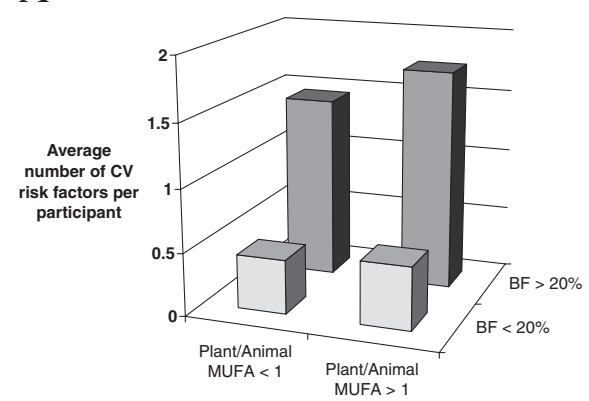

B

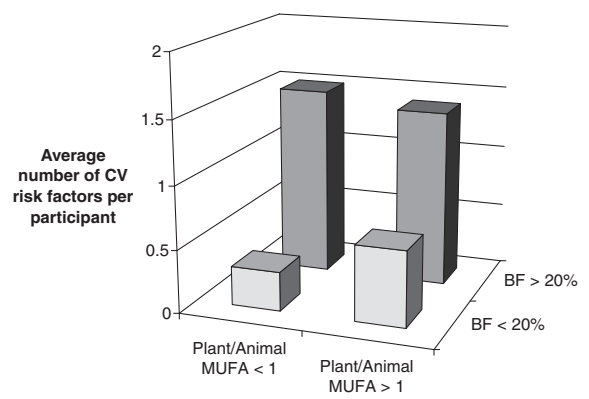

Figure 2 Average number of cardiovascular (CV) risk factors (including waist circumference $>88 \mathrm{~cm}$, physical activity level $<1.8$, diastolic blood pressure $>130 \mathrm{mmHg}$ or systolic blood pressure $>85 \mathrm{mmHg}$, LDL-C/HDL-C ratio $>3.0$ and triglycerides $>1.7 \mathrm{mmol} / \mathrm{L}$ ) according to body fat (BF) percentage and source of monounsaturated fatty acids (MUFA) dietary intake in 25 and 10 men consuming low plant/ animal MUFA ratio $(<1)$ and high plant/animal MUFA ratio $(>1)$, respectively. A using \% of body fat from DEXA to classify study participants into lean (20) or overweight (15) groups. B using \% of body fat from DEXA/m² to classify study participants into lean (18) or overweight (17) groups.

and a greater number of $\mathrm{CV}$ risk factors than lean participants (body fat $<20 \%$ ). Most of the parameters assessed were similar between overweight and lean participants except for higher EI/BW, EE/BMI, PAEE/BW ratios and $\mathrm{VO}_{2 \max }$ in the lean compared to overweight participants using either \%body fat or \%body fat $/ \mathrm{m}^{2}$ to classify the study participants into adiposity levels. Levels of HDL-C were higher in the lean compared to overweight participants using \%body fat to classify participants into adiposity levels but the difference was no longer significant when \%body fat $/ \mathrm{m}^{2}$ was used. Having multiple CV risk factors was more common among those with higher body fatness and lower dietary MUFA intake.

Almost $70 \%$ of the participants had high levels of LDL-C and almost half had low levels of cardio respiratory fitness. Aerobic fitness is an important independent predictor of $\mathrm{CV}$ disease in middle-aged men. Whereas a lower level of fitness has been associated with a 4.7-fold increased risk of myocardial infarction and stroke [11], moderate fitness seems to protect against the influence of other predictors of mortality in adults [33-35]. Other strong independent risk factors for $\mathrm{CV}$ disease include high percentage of body fat [36] and high WC $[37,38]$. Using $88 \mathrm{~cm}$ as a cut-point for WC, $29 \%$ of the participants in this study had high WC.

Results in the current study are consistent with published data from other studies with young men for body fat [39,40], RMR [41-44], EE [41,42], PAL [41,42], BP [45-48], $\mathrm{VO}_{2 \max }[39,49]$, BMI and circumference measurements [50]. BMI is often used to classify subjects in relation to degree of obesity. However this index has limitations as it does not account for variation in body fat distribution and abdominal fat mass [51]. The misclassification of normal and overweight participants using BMI found in the current study is consistent with a previous study [20]. Participants in the current study had better blood lipid profiles including lower TC, LDL$\mathrm{C}$ and TG and higher HDL-C values compared to other studies examining young men [52-54].

Most of the participants in the current study had one or two CV risk factors. Similar findings have been observed in other studies $[55,56]$. Populations with multiple behavioral risk factors are at greatest risk for chronic disease and premature death compared with people with single or no risk factors $[12,57]$ whereas participants with $\mathrm{CV}$ disease were more likely to have three or more CV risk factors (32\%) than those without CV diseases (9.5\%) [58]. The higher levels of risk factors at younger ages in men compared to women leads to $\mathrm{CV}$ disease presenting 10 years later in women [11].

The prevalence of $\mathrm{CV}$ disease has been shown to increase not only with increased number of behavioral risk factors but also with age and obesity level [59]. In addition, obesity was positively associated with the risk of premature death from endogenous causes in populations as young as children supporting the view that childhood obesity is a marker of early metabolic derangement, whereas most of the other risk factors evolve later [60]. Moreover obesity is frequently associated with less favorable biochemical indicators as found in the current study. Lean men in the current study had more favourable biochemical indicators than overweight men. Systolic BP has previously been related to percent body fat $[36,61]$ and obesity, while abdominal obesity and visceral fat have been positively associated with higher TC [7], LDL-C $[7,8]$ and TG $[8,62]$ and negatively associated with HDL-C $[62,63]$. It has been proposed that the mechanism of the link between increased abdominal fat and risk factors for $\mathrm{CV}$ disease is related to higher plasma levels of free fatty acids originating from the enlarged abdominal fat depots [10]. Plasma LDLs cross the vascular endothelium, enter the subendothelial space, become modified and accumulate in 
the macrophages, which are converted into foam cells that progress to form the atherosclerotic plaque [64]. HDL-C may minimize the accumulation of foam cells in the artery wall and inhibit the oxidative modification of LDL-C [64].

Overweight people have been reported to have higher RMR than lean individuals [65-68]. However, overweight and lean men classified by using either \% body fat or \% body fat $/ \mathrm{m}^{2}$ in the current study had similar RMR, possibly due to similar amount of FFM which can contribute up to $80 \%$ of the RMR [69].

In the current study, the mean EI, EE and PAEE were similar in both groups and similar to other studies $[70,71]$. When EI was divided by body weight, the finding of a lower EI per weight observed in overweight men compared to lean men is consistent with other reports [72]. Higher self-reported EI compared to higher self-reported EE for both lean and overweight men suggests underreporting of EI and/or over-re porting of EE which is consistent with other studies [72-74]. This reflects 'the halo effect', where behaviours perceived as 'good' will be over-reported (such as doing physical activity), and those perceived as 'bad' underreported (such as consuming dietary fat). Also consistent with other studies [66-68], that when EE was divided by BMI and PAEE was divided by BW, these ratios were higher in lean compared to overweight men suggesting that the increased energy cost of moving a larger body mass may have contributed to overweight men expending similar amount of energy compared to lean men.

Lean men in the current study had a higher mean $\mathrm{VO}_{2 \max }$ than the overweight men. Increased $\mathrm{VO}_{2 \max }$ has been associated with increased cardio respiratory fitness. The association between reduced cardio respiratory fitness and increased body fat observed in overweight participants in the current study has been reported in other studies [75-77].

The most striking finding of the current study was that participants consuming a diet in which MUFA contributed a high percentage of EI ( $>12 \%$ of the EI) had an average smaller number of $\mathrm{CV}$ disease risk factors compared to those consuming diet in which MUFA contributed to low percentage of EI $(<12 \%$ of the EI). Dietary MUFA have been found to promote a healthy blood lipid profile, mediate blood pressure, and favorably modulate insulin sensitivity and glycemic control [14]. A reduced predicted coronary heart disease risk by $6.37 \%$ was observed in diabetic men consuming a moderately high fat diet (30-50\% of EI) in which MUFA accounted for $23 \%$ of EI compared to diabetic men consuming a low-fat diet (18-30\% of EI) in which MUFA accounted for only $11.4 \%$ of the total EI [16]. A systematic review [78] found that dietary MUFA were associated with a $20 \%$ reduced risk in coronary heart disease events.
The findings of the current study show that intake of MUFA favorably affects CV risk factors regardless of the source. Favorable effects on blood lipids were found in participants of a randomized parallel controlled-feeding trial undertaken by Bos et al. [79] consuming MUFA predominantly from either plant or animal sources. After a two week run-in diet high in saturated fat, participants were allocated to a high MUFA diet primarily from animal sources, a Mediterranean diet in which MUFA were primarily from plant sources, or the high saturated diet for eight weeks. Participants consuming a high MUFA diet predominantly from animal foods had reduced TC and LDL-C whereas participants consuming a high MUFA diet predominantly from plant foods had increased HDL-C and reduced ratio of TC/HDL-C [79].

Use of body fat estimated by DEXA rather than use of BMI to classify the participants into each group was an advantage of the current study. DEXA is the only widely available technology capable of providing regional measures of fat and lean mass, separating body mass into fat and lean components, thereby permitting the evaluation of fat mass without the confounding influence of other tissue constituents [23]. In addition, it has been shown that fat and lean distribution may predict health outcomes [23]. Studies have shown that lean mass and weight scale with height to approximately the power of two, establishing an analytic framework for height-scaled inces. The use of \%body fat $/ \mathrm{m}^{2}$ has been proposed to classify adiposity levels. However it is not known whether or not the use of the proposed \%body fat $/ \mathrm{m}^{2}$ classification scheme will confer benefits over BMI in terms of predicting obesity-related morbidity or mortality. The \%body $\mathrm{fat} / \mathrm{m}^{2}$ classifications were based on prevalence data, not disease risk, and therefore the clinical utility of the \%body fat $/ \mathrm{m}^{2}$ classification scheme will not be known until data relating disease risk to \%body fat $/ \mathrm{m}^{2}$ becomes available [23]. For these reasons we have used both \%body fat and \%body fat $/ \mathrm{m}^{2}$ in order to classify participants of the current study and have showed that there was no difference in the findings using either \%body fat or \%body fat/ $\mathrm{m}^{2}$ to classify the study participants into groups.

A small sample size was a limitation of the current study. Another limitation is that RMR of half of the participants was assessed using different equipment due to technical problems. However the likelihood of measurement bias is small because a similar proportion of lean and overweight participants was assessed using each of the equipments. Nevertheless, the results contribute valuable data from a comprehensive clinical assessment of $\mathrm{CV}$ risk in young Australian men, an important group which has been under-represented in previous work.

Further studies investigating the effect of MUFA consumption including food sources in $\mathrm{CV}$ risk factors in a 
large sample of broader age range, ethnicity and both genders, are warranted.

\section{Conclusions}

It is a serious concern to observe such a high percentage of $\mathrm{CV}$ risk factors in a group of apparently healthy young men. The likelihood of multiple CV risk factors is greater among those with high body fatness and low MUFA intake. Intake of MUFA favorably affects CV risk factors regardless of the source.

\begin{abstract}
Abbreviations
Al: Adequate intake; BP: Blood pressure; BMI: Body mass index; Cardiovascular: CV; DEXA: Dual-energy X-ray absorptiometry; EE: Energy expenditure; El: Energy intake; FFM: Fat-free mass; HDL-C: High density lipoprotein cholesterol; LDL-C: Low density lipoprotein cholesterol; MET: Metabolic equivalents; MUFA: Monounsaturated fatty acids; PAEE: Physical activity energy expenditure; PAL: Physical activity level; RDA: Recommended dietary intake; RMR: Resting metabolic rate; TC: Total cholesterol; TG: triglycerides; UL: Upper limit; $\mathrm{VO}_{2 \text { max }}$ : Maximal oxygen uptake.

\section{Competing interests}

The authors declare that they have no competing interests.

\section{Authors' contributions}

SCL defined the design of the study, undertook data collection, data collation, data analysis and manuscript preparation. LMB helped with the manuscript preparation providing critique and overall scientific input. JB helped with manuscript writing. AH secured support for this study and helped with manuscript writing. All authors read and approved the manuscript.
\end{abstract}

\section{Acknowledgements}

The authors acknowledge Professor Kerin O'Dea for her critical input into the manuscript, the voluntary participants and the Queensland University of Technology for the use of its Laboratories and facilities. SCL acknowledges financial support from the Conselho Nacional de Desenvolvimento Científico e Tecnológico (processo 140931/2001-5) and (processo 201075/03-2). LMB is supported by an Australian NHMRC Early Career Fellowship (605837).

\section{Author details}

'Menzies School of Health Research, Charles Darwin University, Darwin, Australia. ${ }^{2}$ Departamento de Nutrição e Saúde, Universidade Federal de Viçosa, Viçosa, MG, Brazil. ${ }^{3}$ Mater Mother's Hospital/Mater Medical Research Institute, Griffith Health Institute/Griffith University, Brisbane, QLD, Australia.

Received: 30 January 2013 Accepted: 26 July 2013

Published: 1 August 2013

\section{References}

1. Bonow RO, Smaha LA, Smith SC Jr, Mensah GA, Lenfant C: World Heart Day 2002: the international burden of cardiovascular disease: responding to the emerging global epidemic. Circulation 2002, 106:1602-1605.

2. Rubinstein A, Colantonio L, Bardach A, Caporale J, Martí SG, Kopitowski K, Alcaraz A, Gibbons L, Augustovski F, Pichón-Rivière A: Estimation of the burden of cardiovascular disease attributable to modifiable risk factors and cost-effectiveness analysis of preventativeinterventions to reduce this burden in Argentina. BMC Public Health 2010, 10:627-641.

3. Smith SC Jr, Jackson R, Pearson TA, Fuster V, Yusuf S, Faergeman O, Wood DA, Alderman M, Horgan J, Home P, et al: Principles for national and regional guidelines on cardiovascular disease prevention: a scientific statement from the World Heart and Stroke Forum. Circulation 2004, 109:3112-3121.

4. World Health Organization: Noncommunicable diseases. Country profiles 2011. Geneva: World Health Organization; 2011.

5. Dehaven MJ, Ramos-Roman MA, Lee JJ, Gimpel N, Carson J, Delemos J, Pickens S, Simmons C, Powell T, Banks K, et al: The GoodNEWS (Genes, Nutrition, Exercise, Wellness, and Spiritual Growth) Trial: a community-based participatory research (CBPR) trial with African-American church congregations for reducing cardiovascular disease risk factors - recruitment, measurement, and randomization. Contemp Clin Trials 2011.

6. Ouyang P, Sung J, Kelemen MD, Hees PS, DeRegis JR, Turner KL, Bacher AC, Stewart KJ: Relationships of insulin sensitivity with fatness and fitness and in older men and women. Journal of Womens Health (Larchmt) 2004, 13:177-185.

7. DuRant RH, Baranowski T, Rhodes T, Gutin B, Thompson WO, Carroll R, Puhl J, Greaves KA: Association among serum lipid and lipoprotein concentrations and physical activity, physical fitness, and body composition in young children. J Pediatr 1993, 123:185-192.

8. Ward KD, Sparrow D, Vokonas PS, Willett WC, Landsberg L, Weiss ST: The relationships of abdominal obesity, hyperinsulinemia and saturated fat intake to serum lipid levels: the normative aging study. Int $J$ Obes Relat Metab Disord 1994, 18:137-144

9. Ball GDC, Marshall JD, MCCargar LJ: Fatness and fitness in obese children at low and high health risk. Pediatric Exercise Science 2003, 15:392-405.

10. Ohrvall M, Berglund L, Vessby B: Sagittal abdominal diameter compared with other anthropometric measurements in relation to cardiovascular risk. Int J Obes Relat Metab Disord 2000, 24:497-501.

11. Schenck-Gustafsson K: Risk factors for cardiovascular disease in women. Maturitas 2009, 63:186-190.

12. Shah $B$, Mathur $P$ : Surveillance of cardiovascular disease risk factors in India: the need \& scope. Indian Journal of Medical Research 2010, 132:634-642.

13. National Health and Medical Research Council: Nutrient reference values for Australia and New Zealand. Australian Government; 2006.

14. Gillingham LG, Harris-Janz S, Jones PJ: Dietary monounsaturated fatty acids are protective against metabolic syndrome and cardiovascular disease risk factors. Lipids 2011, 46:209-228.

15. National Health and Medical Research Council: Dietary Guidelines for Australian Adults. Canberra: Australian Government; 2003:283.

16. Cao Y, Mauger DT, Pelkman CL, Zhao G, Townsend SM, Kris-Etherton PM: Effects of moderate (MF) versus lower fat (LF) diets on lipids and lipoproteins: a meta-analysis of clinical trials in subjects with and without diabetes. J Clin Lipidol 2009, 3:19-32.

17. Steene-Johannessen J, Kolle E, Anderssen SA, Andersen LB: Cardiovascular disease risk factors in a population-based sample of Norwegian children and adolescents. Scandinavian Journal of Clinical \& Laboratory Investigation 2009, 69:380-386.

18. Liberato SC, Bressan J, Hills AP: A quantitative analysis of energy intake reported by young men. Nutrition \& Dietetics 2008, 65:259-265.

19. De Lorenzo A, Deurenberg P, Pietrantuono M, Di Daniele N, Cervelli V, Andreoli A: How fat is obese? Acta Diabetol 2003, 40(Suppl 1):S254-257.

20. Gallagher D, Heymsfield SB, Heo M, Jebb SA, Murgatroyd PR, Sakamoto Y: Healthy percentage body fat ranges: an approach for developing guidelines based on body mass index. Am J Clin Nutr 2000, 72:694-701.

21. World Health Organization: Physical status: the use and interpretation of anthropometry. In Technical Report Series 854 . Geneva: World Health Organization; 1995:452.

22. Heymsfield SB, Gallagher D, Mayer L, Beetsch J, Pietrobelli A: Scaling of human body composition to stature: new insights into body mass index. Am J Clin Nutr 2007, 86:82-91.

23. Kelly $\mathrm{TL}$, Wilson $\mathrm{KE}$, Heymsfield SB: Dual energy X-Ray absorptiometry body composition reference values from NHANES. PLOS One 2009, 4:e7038.

24. Roffey DM, Byrne NM, Hills AP: Day-to-day variance in measurement of resting metabolic rate using ventilated-hood and mouthpiece \& nose-clip indirect calorimetry systems. JPEN J Parenter Enteral Nutr 2006, 30:426-432.

25. O'Neil CE, Fulgoni VL 3rd, Nicklas TA: Candy consumption was not associated with body weight measures, risk factors for cardiovascular disease, or metabolic syndrome in US adults: NHANES 1999-2004. Nutr Res 2011, 31:122-130.

26. Nauck M, Graziani MS, Bruton D, Cobbaert C, Cole TG, Lefevre F, Riesen W, Bachorik PS, Rifai N: Analytical and clinical performance of a detergent-based homogeneous LDL-cholesterol assay: a multicenter evaluation. Clin Chem 2000, 46:506-514

27. Millan J, Pinto $X$, Munoz A, Zuniga M, Rubies-Prat J, Pallardo LF, Masana L, Mangas A, Hernandez-Mijares A, Gonzalez-Santos P, et al: Lipoprotein ratios: physiological significance and clinical usefulness in cardiovascular prevention. Vasc Health Risk Manag 2009, 5:757-765. 
28. National Heart Foundation of Australia: Position Statement on Lipid Management-2005. Australia/New Zealand: Australasian Society of Cardiac and Thoracic Surgeons and the Cardiac Society of Australia and New Zealand; 2005:17.

29. Bouchard C, Tremblay A, Leblanc C, Lortie G, Savard R, Theriault G: A method to assess energy expenditure in children and adults. American Journal of Clinical Nutrition 1983, 37:461-467.

30. Borg E: Physical performance and perceived exertion. In Studia Psychologica et Paedogogica. Investigationes XI Lund. Sweeden: Gleerup; 1962.

31. Cabré J-J, Martín F, Costa B, Piñol JL, Llor JL, Ortega Y, Basora J, Baldrich M, Solà R, Daniel J, et al: Metabolic syndrome as a cardiovascular disease risk factor: patients evaluated in primary care. BMC Public Health 2008, 8:251-262.

32. Scrimshaw NS, Waterlow JC, Schürch B: Energy and Protein requirements, Proceedings of an IDECG workshop. London: International Dietary Energy Consultative Group; 1994

33. Blair SN, Kohl HW 3rd, Barlow CE, Paffenbarger RS Jr, Gibbons LW, Macera $\mathrm{CA}$ : Changes in physical fitness and all-cause mortality. A prospective study of healthy and unhealthy men. Journal of the American Medical Association 1995, 273:1093-1098.

34. Blair SN, Kampert JB, Kohl HW 3rd, Barlow CE, Macera CA, Paffenbarger RS Jr, Gibbons LW: Influences of cardiorespiratory fitness and other precursors on cardiovascular disease and all-cause mortality in men and women. Journal of the American Medical Association 1996, 276:205-210.

35. Wedderkopp N, Froberg K, Hansen HS, Riddoch C, Andersen LB: Cardiovascular risk factors cluster in children and adolescents with low physical fitness: The European Youth Heart Study (EYHS). Pediatric Exercise Science 2003, 15:419-427.

36. Ebesunun MO, Agbedana EO, Taylor GOL, Oladapo OO: Plasma lipoprotein (a), homocysteine, and other cardiovascular disease (CVD) risk factors in Nigerians with CVD. Applied Physiology, Nutrition \& Metabolism 2008, 33:282-289

37. Dalton M, Cameron AJ, Zimmet PZ, Shaw JE, Jolley D, Dunstan DW, Welborn TA: Waist circumference, waist-hip ratio and body mass index and their correlation with cardiovascular disease risk factors in Australian adults. J Intern Med 2003, 254:555-563.

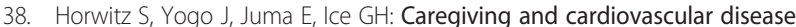
risk factors in male and female Luo elders from Kenya. Annals of Human Biology 2009, 36:400-410

39. Ho RC, Davy KP, Hickey MS, Summers SA, Melby CL: Behavioral, metabolic, and molecular correlates of lower insulin sensitivity in MexicanAmericans. American Journal of Physiology-endocrinology and Metabolism 2002, 283:E799-808

40. Park YW, Heymsfield SB, Gallagher D: Are dual-energy X-ray absorptiometry regional estimates associated with visceral adipose tissue mass? Int J Obes Relat Metab Disord 2002, 26:978-983.

41. Conway JM, Seale JL, Jacobs DR Jr, Irwin ML, Ainsworth BE: Comparison of energy expenditure estimates from doubly labeled water, a physical activity questionnaire, and physical activity records. Am J Clin Nutr 2002, 75:519-525.

42. Westerterp KR, Goran MI: Relationship between physical activity related energy expenditure and body composition: a gender difference. International Journal of Obesity 1997, 21:184-188.

43. Goran MI, Calles-Escandon J, Poehlman ET, O'Connell M, Danforth E Jr: Effects of increased energy intake and/or physical activity on energy expenditure in young healthy men. J Appl Physiol 1994, 77:366-372.

44. Hise ME, Sullivan DK, Jacobsen DJ, Johnson SL, Donnelly JE: Validation of energy intake measurements determined from observer-recorded food records and recall methods compared with the doubly labeled water method in overweight and obese individuals. Am J Clin Nutr 2002, 75:263-267.

45. Figueroa A, Trivino JA, Sanchez-Gonzalez MA, Vicil F: Oral L-citrulline supplementation attenuates blood pressure response to cold pressor test in young men. Am J Hypertens 2010, 23:12-16.

46. Lubkowska A, Szygula Z: Changes in blood pressure with compensatory heart rate decrease and in the level of aerobic capacity in response to repeated whole-body cryostimulation in normotensive, young and physically active men. Int J Occup Med Environ Health 2010, 23:367-375.

47. Miyashita M, Burns SF, Stensel DJ: Accumulating short bouts of brisk walking reduces postprandial plasma triacylglycerol concentrations and resting blood pressure in healthy young men. Am J Clin Nutr 2008, 88:1225-1231.
48. Wakabayashi I: Blood HDL cholesterol levels influence association of alcohol intake with blood pressure in young men but not in middle-aged men. Alcohol Clin Exp Res 2007, 31:1552-1557.

49. Santo AS, Golding LA: Predicting maximum oxygen uptake from a modified 3-minute step test. Res Q Exerc Sport 2003, 74:110-115.

50. McLennan W, Podger A: National Nutrition Survey. Nutrient Intakes and Physical Measurements. In ABS publications. Canberra: Australian Bureau of Statistics and Department of Health and Aged Care; 1995:1-170.

51. Wong SL, Katzmarzyk P, Nichaman MZ, Church TS, Blair SN, Ross R: Cardiorespiratory fitness is associated with lower abdominal fat independent of body mass index. Med Sci Sports Exerc 2004, 36:286-291.

52. Gan SK, Kriketos AD, Ellis BA, Thompson CH, Kraegen EW, Chisholm DJ: Changes in aerobic capacity and visceral fat but not myocyte lipid levels predict increased insulin action after exercise in overweight and obese men. Diabetes Care 2003, 26:1706-1713.

53. Singh RB, Niaz MA, Ghosh S, Beegom R, Agarwal P, Nangia S, Moshiri M, Janus ED: Low fat intake and coronary artery disease in a population with higher prevalence of coronary artery disease: the Indian paradox. J Am Coll Nutr 1998, 17:342-350.

54. van der Kooy K, Leenen R, Seidell JC, Deurenberg P, Visser M: Abdominal diameters as indicators of visceral fat: comparison between magnetic resonance imaging and anthropometry. Br J Nutr 1993, 70:47-58.

55. Jernigan VB, Duran B, Ahn D, Winkleby M: Changing patterns in health behaviors and risk factors related to cardiovascular disease among American Indians and Alaska Natives. Am J Public Health 2010, 100:677-683.

56. Kourlaba G, Polychronopoulos E, Zampelas A, Lionis C, Panagiotakos DB Development of a diet index for older adults and its relation to cardiovascular disease risk factors: the elderly dietary index. J Am Diet Assoc 2009, 109:1022-1030.

57. Heinrich KM, Maddock J: Multiple health behaviors in an ethnically diverse sample of adults with risk factors for cardiovascular disease. Perm J 2011, 15:12-18.

58. Li C, Ford ES, Mokdad AH, Balluz LS, Brown DW, Giles WH: Clustering of cardiovascular disease risk factors and health-related quality of life among US adults. Value Health 2008, 11:689-699.

59. Cardi M, Munk N, Zanjani F, Kruger T, Schaie KW, Willis SL: Health behavior risk factors across age as predictors of cardiovascular disease diagnosis. J Aging Health 2009, 21:759-775.

60. Franks PW, Hanson RL, Knowler WC, Sievers ML, Bennett PH, Looker HC: Childhood obesity, other cardiovascular risk factors, and premature death. N Engl J Med 2010, 362:485-493.

61. De Pergola G, Pannacciulli N, Ciccone M, Tartagni M, Rizzon P, Giorgino R: Free testosterone plasma levels are negatively associated with the intima-media thickness of the common carotid artery in overweight and obese glucose-tolerant young adult men. Int J Obes Relat Metab Disord 2003, 27:803-807.

62. Nguyen-Duy TB, Nichaman MZ, Church TS, Blair SN, Ross R: Visceral fat and liver fat are independent predictors of metabolic risk factors in men. American Journal of Physiology-endocrinology and Metabolism 2003, 284: E1065-1071

63. Summers LK, Fielding BA, Bradshaw HA, Ilic V, Beysen C, Clark ML, Moore NR, Frayn KN: Substituting dietary saturated fat with polyunsaturated fat changes abdominal fat distribution and improves insulin sensitivity. Diabetologia 2002, 45:369-377.

64. Barter P, Best J, Boyden A, Cooper C, Gillam I: Lipids management guidelines. The Medical Journal of Australia 2001, 175:S57-S88.

65. DeLany JP, Bray GA, Harsha DW, Volaufova J: Energy expenditure in African American and white boys and girls in a 2-y follow-up of the Baton Rouge Children's Study. Am J Clin Nutr 2004, 79:268-273.

66. Ekelund U, Aman J, Yngve A, Renman C, Westerterp K, Sjostrom M: Physical activity but not energy expenditure is reduced in obese adolescents: a case-control study. Am J Clin Nutr 2002, 76:935-941.

67. Prentice AM, Black AE, Coward WA, Davies HL, Goldberg GR, Murgatroyd PR, Ashford J, Sawyer M, Whitehead RG: High levels of energy expenditure in obese women. Br Med J (Clin Res Ed) 1986, 292:983-987.

68. Seidell JC, Muller DC, Sorkin JD, Andres R: Fasting respiratory exchange ratio and resting metabolic rate as predictors of weight gain: the Baltimore longitudinal study on aging. Int J Obes Relat Metab Disord 1992, 16:667-674. 
69. Sallis JF, Patterson TL, Buono MJ, Nader PR: Relation of cardiovascular fitness and physical activity to cardiovascular disease risk factors in children and adults. Am J Epidemiol 1988, 127:933-941.

70. Andersson I, Rossner S: The Gustaf study: repeated, telephoneadministered 24-hour dietary recalls of obese and normal-weight men-energy and macronutrient intake and distribution over the days of the week. J Am Diet Assoc 1996, 96:686-692.

71. Baecke JA, van Staveren WA, Burema J: Food consumption, habitual physical activity, and body fatness in young Dutch adults. Am I Clin Nutr 1983, 37:278-286.

72. Miller WC: Diet composition, energy intake, and nutritional status in relation to obesity in men and women. Med Sci Sports Exerc 1991, 23:280-284.

73. Johansson G, Wikman A, Ahren AM, Hallmans G, Johansson I: Underreporting of energy intake in repeated 24-hour recalls related to gender, age, weight status, day of interview, educational level, reported food intake, smoking habits and area of living. Public Health Nutr 2001, 4:919-927.

74. Johansson L, Solvoll K, Bjorneboe GE, Drevon CA: Under- and overreporting of energy intake related to weight status and lifestyle in a nationwide sample. Am J Clin Nutr 1998, 68:266-274.

75. Bergstrom $E$, Hernell $O$, Persson LA: Endurance running performance in relation to cardiovascular risk indicators in adolescents. Int I Sports Med 1997, 18:300-307.

76. Janssen I, Katzmarzyk PT, Ross R, Leon AS, Skinner JS, Rao DC, Wilmore JH, Rankinen T, Bouchard C: Fitness alters the associations of BMI and waist circumference with total and abdominal fat. Obes Res 2004, 12:525-537.

77. Dreon DM, Frey-Hewitt B, Ellsworth N, Williams PT, Terry RB, Wood PD: Dietary fat: carbohydrate ratio and obesity in middle-aged men. The American Journal of Clinical Nutrition 1988, 47:995-1000

78. Mente A, de Koning L, Shannon HS, Anand SS: A systematic review of the evidence supporting a causal link between dietary factors and coronary heart disease. Arch Intern Med 2009, 169:659-669.

79. Bos MB, de Vries JH, Feskens EJ, van Dijk SJ, Hoelen DW, Siebelink E, Heijligenberg R, de Groot LC: Effect of a high monounsaturated fatty acids diet and a Mediterranean diet on serum lipids and insulin sensitivity in adults with mild abdominal obesity. Nutr Metab Cardiovasc Dis 2010, 20:591-598.

doi:10.1186/1475-2891-12-108

Cite this article as: Liberato et al.: The relationships between body composition and cardiovascular risk factors in young Australian men. Nutrition Journal 2013 12:108.

\section{Submit your next manuscript to BioMed Central and take full advantage of:}

- Convenient online submission

- Thorough peer review

- No space constraints or color figure charges

- Immediate publication on acceptance

- Inclusion in PubMed, CAS, Scopus and Google Scholar

- Research which is freely available for redistribution 